\title{
Chapter 16 \\ The Bicycle and the Arctic - Resilient and Sustainable Transport in Times of Climate Change
}

\author{
Alexander Meitz and Karoline Ringhofer
}

\begin{abstract}
In Alaska, alternative transport modes to cars and other motorized, petrol powered vehicles are gaining in importance due to increasing urbanization and as adaptive responses to risks of infrastructural damage to transportation networks in facing the climate change. Bicycling functions as a transportation practice in response to increasing infrastructure disruptions, offering a strategy towards sustainable and resilient means of transportation in the times of global climate change and its associated challenges. Changing weather conditions and demographic changes lead to the necessity to establish more adapted infrastructures. The use of the bicycle hereby offers a suitable mode of transport in Arctic and Subarctic areas. New technologies such as fat bikes make bicycling throughout the winter season possible. The combination of the theoretical concepts of sustainability and resilience bears the potential to foster concrete solutions and action strategies for policy makers with respect to infrastructural challenges in the Arctic.
\end{abstract}

\subsection{Introduction}

Contrary to popular opinion, the bicycle is not a new phenomenon in Alaska. During the gold rush at the turn of the last century (1898-1908) it was used as a means of transport not only in commuting trips but also in long distances like Dawson (Yukon, Canada) to Nome (Alaska, USA), covering more than $1200 \mathrm{~km} / 772 \mathrm{mi}$ (Cole 1985). More than a 100 years later, in summer season, cyclists are spotted frequently commuting in Alaska's urban areas and using the bicycle as leisure activity. Moreover, even in Alaska's particular environmental conditions, winter cycling is becoming

\footnotetext{
A. Meitz $(\bowtie) \cdot K$. Ringhofer

Department of Social and Cultural Anthropology, University of Vienna, Vienna, Austria e-mail: alexander.meitz@univie.ac.at; karoline.ringhofer@gmail.com
} 
increasingly popular not only as sports and recreation, but also as commuting device due to newly developed technologies, new bicycle lanes separated from car traffic, and federal grant programs such as the Safe Routes to School (SRTS) or the AMATS $^{1}$ Bike Plan Implementation Project (CRW Engineering Group 2017).

This chapter presents preliminary results from an ongoing research that focuses on urban bicycling in Alaska. The research design includes interviews with bicycle commuters, policy makers, bicycle advocacy organizations and many hours of participant observation on wheels, immersing in the field and directly experiencing the particular conditions of cycling in Anchorage and Fairbanks in both summer and winter. Additional research would ideally incorporate interdisciplinary collaboration, as changing conditions in the Arctic and Subarctic require "knowledge of geomorphological processes ... and of infrastructure design and function" (Hovelsrud et al. 2010), as well as an anthropological perspective, giving attention to the local population's vulnerability and adaptive capacity towards these changes.

\subsection{Theoretical Framework}

Bicycling is frequently linked with notions of sustainability due to its energyefficiency and the fact that its use doesn't produce any carbon emissions. The concept of sustainability itself refers to "the long-term ability to continue to engage in a particular activity, process or use of natural resources" (Benson and Craig 2014, 778). Its main drawback however is that this concept relies on a predictable economic and social development and that it is based on the assumption that there exist maintainable equilibrium states of socioeconomic and ecological systems within the earth's carrying capacity. An example which illustrates this notion stems from sustainable forest management, stating that one should not cut down more trees than can grow back over the same period of time. Yet, in times of climate change our world is confronted with uncertainty. Systems are in process of adaptation and transformation. Global climate change, the loss of biodiversity and the constant increase of the per capita consumption of resources create a high probability of rapid, dynamic and non-linear changes in social and ecological systems (Benson and Craig 2014, 777). Non-linearity refers to the possibility that climate processes can abruptly accelerate or slow down. Due to this uncertainty, it is argued here, that sustainability has to be combined with a resilience-approach in order to have an adequate analytical tool at hand in the face of future challenges. Resilience is a concept to account for the capacity of a system to cope with change, i.e. stress on the respective system. It is a "measure of the amount of change the system can undergo and still retain the same controls on function and structure" (Berkes and Jolly 2002). Adaptive capacity as it is used here "refers to the underlying capacity to adjust to changing conditions, it can be considered an important expression of resilience" (Arctic Resilience Report 2016, 9). The concept of resilience alone however has the disadvantage that also unsustainable system configurations may

${ }^{1}$ Anchorage Metropolitan Area Transportation Solutions 
prove to be resilient. Thus, it is the combination of both concepts which allows for a long-term sustainable solution which also buffers from external shocks. In the present research, aspects of sustainability and resilience as discussed regarding the use of the bicycle in Alaska's urban areas.

\subsection{The Bicycle in Urban Alaska}

The relevance of sustainable and resilient modes of transport in Alaska's urban areas stems from the trend towards increasing urbanization in the region. "In urban areas, the demand for pedestrian, bicycle, and transit travel is increasing and this is expected to continue as the State's population becomes more concentrated in urban areas" (Facilities 2016). Geophysical processes of climate change expedite these migratory movements (Hovelsrud et al. 2010). As more and more people are moving to urbanized areas, questions about mobility and infrastructure ${ }^{2}$ become prevalent for decision makers (Norden 2011). In 1995, the Department of Transportation and Public Facilities (DOT\&PF) presented its first bicycle and pedestrian plan which is an integral part of the 'Vision: 2020 Alaska's Long-Range Statewide Transportation Plan'. Now, 22 years later, an updated version is available. The policy plan 'Let's keep moving 2036' addresses increasing bicycling demands in urban areas.

It is argued here that the bicycle offers an adaptive strategy towards increasing urbanization in Alaska and future climate-induced challenges. Although currently only a marginal percentage of less than $2.5 \%{ }^{3}$ of Anchorage's commuters are using the bicycle as means of transportation to work, it has the potential to offer an interesting alternative for Arctic and Subarctic cities. Being unfamiliar with the topic, one might reason that Alaska's long winters impede the use of the bicycle. Yet, Minneapolis, whose winter conditions are comparable to those of Alaska's urban regions, is a top-ranked bicycle city with almost $6 \%$ of the population commuting (United States Census Bureau 2016). In the European Arctic, the percentage of cyclists even is considerably higher. The city of Oulu in Finland and city of Umeå in Sweden both with an overall bicycle modal share at around 20\% (EPOMM 2017) show that bicycle infrastructure combined with the provision of public transportation and community attitudes, public support and pro-bike policies are as important factors influencing the use of the bicycle, as topography or climate (Bergström and Magnusson 2003).

Besides political, legal and infrastructural aspects, new technologies facilitate the use of the bicycle in the Arctic. Terrence Cole comments on winter cycling during the beginning of the 20th century:

\footnotetext{
${ }^{2}$ Infrastructure, as it is used here, refers to transportation networks.

${ }^{3}$ The number stems from the 'Regional Household Travel Survey 2014'. An actual number of cyclists is not yet available. The Anchorage Bike Community just installed their first bike counter in September 2016 and in combination with bike-tracking software such as STRAVA they will be able to get more comprehensive data.
} 
In the low temperatures, bearings would freeze and the tires get stiff. A fall on the ice when the temperature was far below zero could easily shatter a pedal or a handlebar, or a knee or an elbow. For good reason most of the men whose stories are included in this book were thought to be a little mentally deranged (Cole 1985).

Even nowadays, non-cyclists react in a similar way if asked for their opinion on people who commute by bicycle in winter. Nevertheless, today's bicycle technology is way more capable to handle temperatures far below zero Fahrenheit. The introduction of fat bikes (Fig. 16.1) to Alaska makes bicycling in the winter season possible, as their design enables these off-road bicycles to ride on unstable ground such as mud and snow and therefore being able to use unpaved mountain bike singletracks ${ }^{4}$ for commuting. In year 2000, fat bike tires with a width of at least 3.8 inches/97 $\mathrm{mm}$ appeared on the market. Reduced tire pressure brings more of the tire's surface area in contact with the ground, allowing the cyclist to ride on soft terrain, and is thus perfectly suited for winter cycling in the Arctic. It is a low-cost solution for citizens in comparison to the costs of a car, but not barrier-free in terms of physical requirements. Congruent with the literature dealing with bicycling in northern cities such as Rotterdam and Vermont (Böcker and Thorsson 2014; Spencer et al. 2013), precipitation, cold temperatures, wind and limited daylight are among the major factors which deter people from using the bicycle all around the year. Northern weather conditions pose obstacles concerning comfort and safety, with an

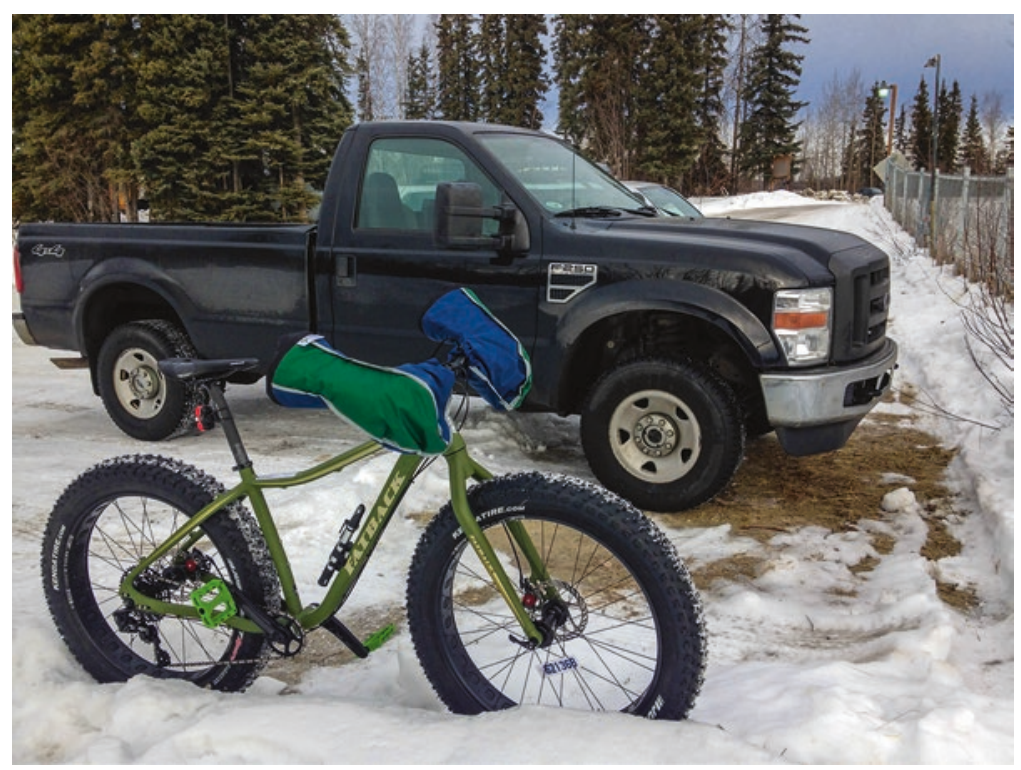

Fig. 16.1 Fat bike in Fairbanks, Alaska (Photo: A. Meitz)

\footnotetext{
${ }^{4}$ Singletracks are about the width of the bicycle and therefore not accessible for motorized vehicles.
} 
increased risk of accidents due to icy paths, non-existing or badly maintained bicycle infrastructure and darkness. These factors dissuade many cyclists from commuting in winter season, leaving winter cycling to the most entrenched idealists, who perceive all-year bicycling as lifestyle choice. The specific weather conditions add to an understanding why it is unlikely for bicycling to form a major proportion of transportation in Arctic areas. Another disadvantage in its use is its limited capacity of transporting large goods. Although there exist cargo bicycles, winter conditions impede their usage. Cold temperatures, wind and precipitation further pose challenges to carry children in seats and carriages, making bicycling in the Arctic's winter conditions a family-unfriendly undertaking. Even if the bicycle presents an inexpensive mode of transport - especially in comparison to motorized vehicles - the costs to set up the winter equipment (including fat bike and outfit) vary between US-\$3000-4000, which equals roughly the average monthly income in Alaska.

It is widely known that bicycling presents an energy-efficient mode of transport in the sense that it is human-powered, offering a beneficial cardiovascular exercise (Pucher and Buehler 2008, 496). Its use is not dependent on fuel, bicycle lanes need less space than paved roads for cars, their maintenance costs less money, and needs less resources. Especially for urban areas with increasing traffic, bicycling has the key benefit of producing zero emissions, contributing to improved air quality. Further, it has the potential to reduce noise pollution and promotes an active lifestyle, which reflects itself in the use of the bicycle for recreation and physical activity. Sport lovers seek out unpaved terrain in woodlands and snow conditions, and the tourism sector heavily relies on this perpetuated image of wilderness and adventure.

Analyzing the bicycle's adaptive capacity towards changing conditions provides us with information about this mode of transportation's resilience towards climate perturbations. The root of the resilience of bicycling stems from the fact that cyclists can create and shape their own tracks. They are not as dependent on paved roads as cars, but can move on gravel roads in summer and packed snow trails in winter season, which get created gradually by the cyclists themselves due to the applicability of fat bikes on unstable and soft grounds. An interesting aspect here comes with the fact that the creation of packed snow trails is flexible and shows adaptive potential. In case of bad road maintenance like uncleared bike lanes or piles of snow created by snow ploughs, snow conditions enable cyclists (especially those using fat bikes) to create their own tracks, shaping them to their necessities. This aspect makes them much less dependent on infrastructure provided by the municipality.

Further, bicycling offers an adaptive response towards widely reported changing weather conditions in the Arctic. In the context of Alaska, these changes manifest themselves in unusually warm temperatures and decreased precipitation (Wendler and Shulski 2009, 300), accompanied by non-linear events such as sudden disruptions like landslides stemming from thawing permafrost grounds, snow avalanches and variability in snowfall, which affect mobility. Snowfall is subject to increased uncertainty because of changing frequency, timing and intensity such as occasional unusually heavy snowfall and wider fluctuations with more frequent alternations of thaw and freeze periods. A longer transition between the seasons with repeated freeze-thaw-cycles makes road maintenance with snow and ice control more com- 
plicated and costly. The use of bicycles offers a resilient commuting strategy, as fat bikes do not depend on road clearance and are especially designed for snow. This characteristic makes winter cycling an adaptive strategy towards sudden snowfalls, in situations where cars are much more dependent on external help. Further, in thawing cycles fat bikes can easily maneuver over muddy terrains. This aspect enables the use of the bicycle in the context of increasing temperatures, as unpaved lanes (Fig. 16.2) remain accessible for cyclists, even in the case of melting snow and soft, wet, unstable soil such as thawing permafrost grounds. For icy roads there exist studded tires, making all-year round cycling possible. Another feature regarding the adaptive capacity of cyclists is their resilience towards road obstructions. If roads get blocked due to unexpected geomorphological events such as landslides or fallen trees, cyclists can easily make their way around obstacles. All these aspects prove the high adaptability of the bicycle in the face of increasing climate variability. All around the circumpolar north, thawing permafrost will lead to increased costs in road maintenance (U.S. Arctic Research Commission Permafrost Task Force 2003). In Alaska "uneven sinking of the ground in response to permafrost thaw is estimated to add between $\$ 3.6$ and $\$ 6.1$ billion (10-20\%) to current costs of maintaining public infrastructure such as buildings, pipelines, roads, and airports over the next 20 years." (Chapin et al. 2014, 520). Even if roads fall into disrepair, people with fat bikes will continue to be able to transport themselves.

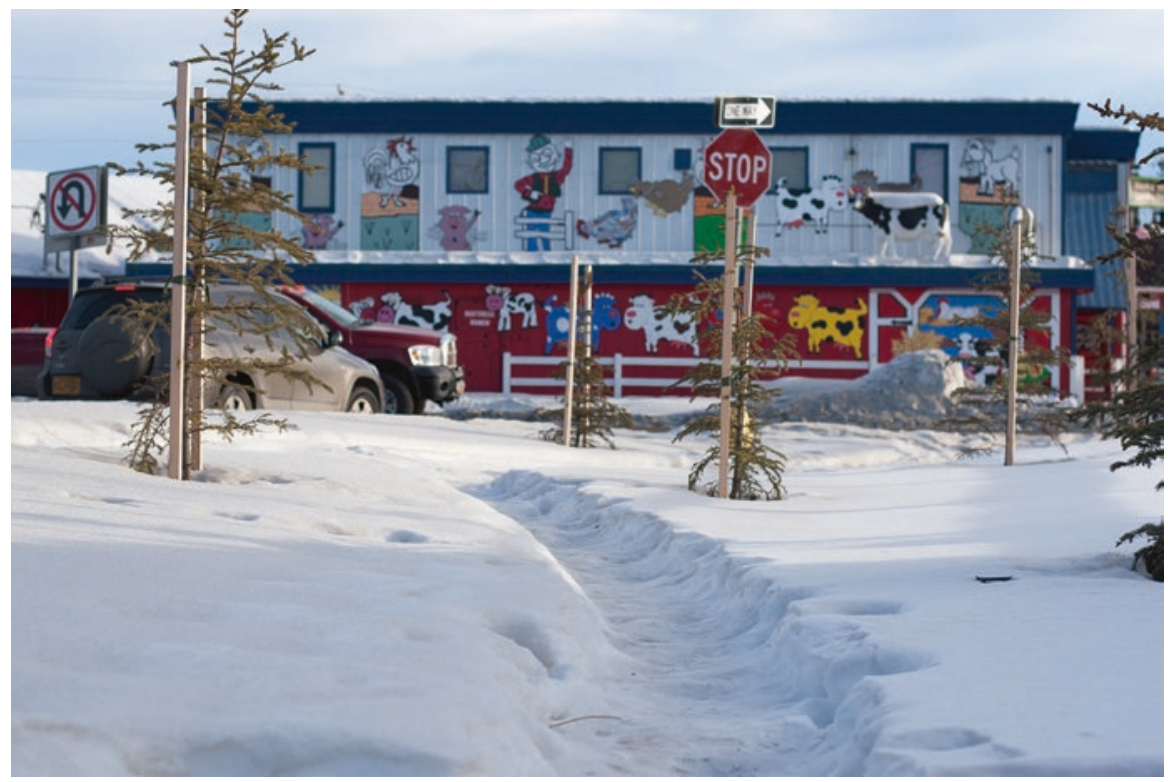

Fig. 16.2 An unpaved path with packed snow created by cyclists and pedestrians in Fairbanks, Alaska (Photo: A. Meitz) 
Although Alaska's urban regions are not directly affected ${ }^{5}$, this aspect is insofar of relevance as melting permafrost is one of the reasons for increasing migration from high-risk areas.

\subsection{Conclusion}

The trend towards urbanization in Alaska raises questions about mobility, means of transportation and infrastructure. The bicycle offers a sustainable commuting device, reduces traffic, emissions, noise pollution and contributes to better air quality in cities. Its usage is however to be seen with restrictions, as it is neither an option for people with limitations, nor for transporting big masses. Cold temperatures, precipitation and limited daylight hours further deter people from the use of the bicycle due to discomfort and safety concerns. Because of these disadvantages, it might never form a major proportion of transportation in Arctic winter conditions, but offers certain adaptability advantages towards changing weather conditions in comparison to car users. This aspect constitutes the bicycle's resilience factor, as its use is less dependent on paved and well-maintained roads and it can ride on unstable terrain such as snow and mud. Bicycles have more flexible maneuverability than cars - and that quality can be particularly useful in the Arctic with its more variable and changing weather conditions. Due to its applicability on various terrains, the use of the bicycle makes it possible to circumvent road obstructions, and to be less dependent on road maintenance. The local practice of all-year cycling in other Arctic and Subarctic regions with comparably high levels of cycling due to well developed bicycle infrastructure and pro-bike policies can be instructive for policy makers in Anchorage and Fairbanks. Moreover, bicycling in the north presents an attractive leisure activity and forms part of the eco-tourism in the Arctic. In the long run, bicycle infrastructure and the idea of a complete street design can help city governments to create an infrastructure with safe access for all users. Bicycling as a sustainable and resilient means of transportation is - against expectations - a feasible option for commuters in the circumpolar north.

\section{References}

Benson MH, Craig RK (2014) The end of sustainability. Soc Nat Resour 27:777-782. doi:10.108 0/08941920.2014.901467

Bergström A, Magnusson R (2003) Potential of transferring car trips to bicycle during winter. Transp Res A Policy Pract 37:649-666. doi:10.1016/S0965-8564(03)00012-0

Berkes F, Jolly D (2002) Adapting to climate change: social-ecological resilience in a Canadian western Arctic community. Conserv Ecol 5:18 ${ }^{5}$ Fairbanks area is not a high hazard zone, with only discontinuous permafrost, but future disrup-
tions may occur such as road damages due to moving grounds. 
Böcker L, Thorsson S (2014) Integrated weather effects on cycling shares, frequencies, and durations in Rotterdam, the Netherlands. Weather Clim Soc 6:468-481. doi:10.1175/ WCAS-D-13-00066.1

Chapin FS III, Trainor SF, Cochran P, Huntington H, Markon C, McCammon M, McGuire AD, Serreze M (2014) Ch. 22: Alaska. Climate Change Impacts in the United States: The Third National Climate Assessment, In: Melillo JM, Richmond T, Yohe GW (eds), U.S. Global Change Research Program, pp. 514-536. doi:10.7930/J00Z7150

Cole T (1985) Wheels on Ice - Bicycling in Alaska 1898-1908. Alaska Northwest Publishing Company.

CRW Engineering Group L (2017) AMATS. http://www.anchoragebikeplan.com. Accessed 02.01.2017

EPOMM (2017) TEMS - The EPOMM Modal Splitt Tool. http://www.epomm.eu/tems/cities. phtml. Accessed 01.02.2017 2017

Facilities TaP (2016) Let's keep moving 2036: policy plan. Alaska Statewide Longe-Range Transportation Plan

Hovelsrud GK, White JL, Andrachuk M, Smit B (2010) Community adaptation and vulnerability integrated. In: Hovelsrud GK, Smit B (eds) Community Adaptation and Vulnerability in Arctic Regions. Springer, Heidelberg, pp 335-348

Norden (2011) Megatrends. Team Nord, 2011 edn. Danish Ministry of Foreign Affairs, Copenhagen. doi:http://dx.doi.org/10.6027/tn2011-527

Pucher J, Buehler R (2008) Making cycling irresistible: lessons from the Netherlands, Denmark and Germany. Transp Rev 28:495-528. doi:10.1080/01441640701806612

Spencer P, Watts R, Vivanco L, Flynn B (2013) The effect of environmental factors on bicycle commuters in Vermont: influences of a northern climate. J Transp Geogr 31:11-17. doi:10.1016/j. jtrangeo.2013.05.003

U.S. Arctic Research Commission Permafrost Task Force (2003) Climate change, permafrost, and impacts on civil infrastructure. Special Report 01-03, U.S. Arctic Research Commission, Arlington, Virginia

Wendler G, ShulSki M (2009) A century of climate change for Fairbanks, Alaska. Arctic:295-300

Open Access This chapter is licensed under the terms of the Creative Commons Attribution 4.0 International License (http://creativecommons.org/licenses/by/4.0/), which permits use, sharing, adaptation, distribution and reproduction in any medium or format, as long as you give appropriate credit to the original author(s) and the source, provide a link to the Creative Commons license and indicate if changes were made.

The images or other third party material in this chapter are included in the chapter's Creative Commons license, unless indicated otherwise in a credit line to the material. If material is not included in the chapter's Creative Commons license and your intended use is not permitted by statutory regulation or exceeds the permitted use, you will need to obtain permission directly from the copyright holder.

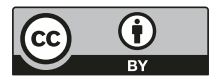

